\title{
BASF startet Bau der TDI-Anlage
}

$\mathrm{M}$

it einem offiziellen Spatenstich gaben am 23. November 2012 Margret Suckale, BASF-Vorstandsmitglied und Standortleiterin Ludwigshafen, Raimar Jahn, Leiter des Unternehmensbereichs Polyurethanes, und Dr. Bernhard Nick, Werksleiter Verbundstandort Ludwigshafen, das Signal für den Baubeginn der Anlage zur Herstellung von TDI (Toluoldiisocyanat). Wie berichtet, wird die Gesamtinvestition einschließlich der erforderlichen Infrastruktur und Vorstufen rund 1 Milliarde $€$ betragen und mehr als 200 neue Arbeitsplätze schaffen. Die TDI-Produktionsanlage hat eine Kapazität von 300.000 Tonnen pro Jahr und soll Ende 2014 den Betrieb aufnehmen. Margret Suckale bezeichnete den Bau der TDI-Anlage als wesentlichen Beitrag zur Weiterentwicklung des Standorts Ludwigshafen. Die Investition sei ein klares Bekenntnis des Unternehmens zu Lud-

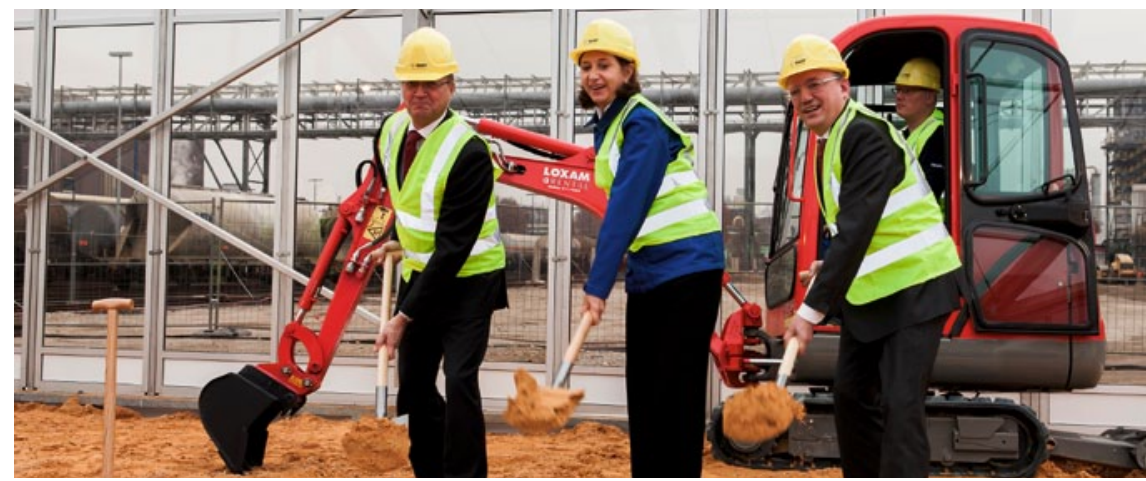

Mit einem offiziellen Spatenstich gaben am 23. November 2012 Raimar Jahn, Leiter des Unternehmensbereichs Polyurethanes, Margret Suckale, BASF-Vorstandsmitglied und Standortleiterin Ludwigshafen, und Dr. Bernhard Nick, Werksleiter Verbundstandort Ludwigshafen, (v. I. n. r.) das Signal für den Baubeginn der Anlage zur Herstellung von TDI am Standort Ludwigshafen (Foto: BASF).

wigshafen mit positiven Auswirkungen für die gesamte Region und die komplette Infrastruktur vor Ort. Mit dieser Investition wird die BASF über zwei starke Standorte für Polyurethan-Grundpro- dukte in Europa verfügen: Ludwigshafen für die Produktion von TDI und Antwerpen für die Produktion von MDI (Diphenylmethandiisocyanat) und Propylenoxid.
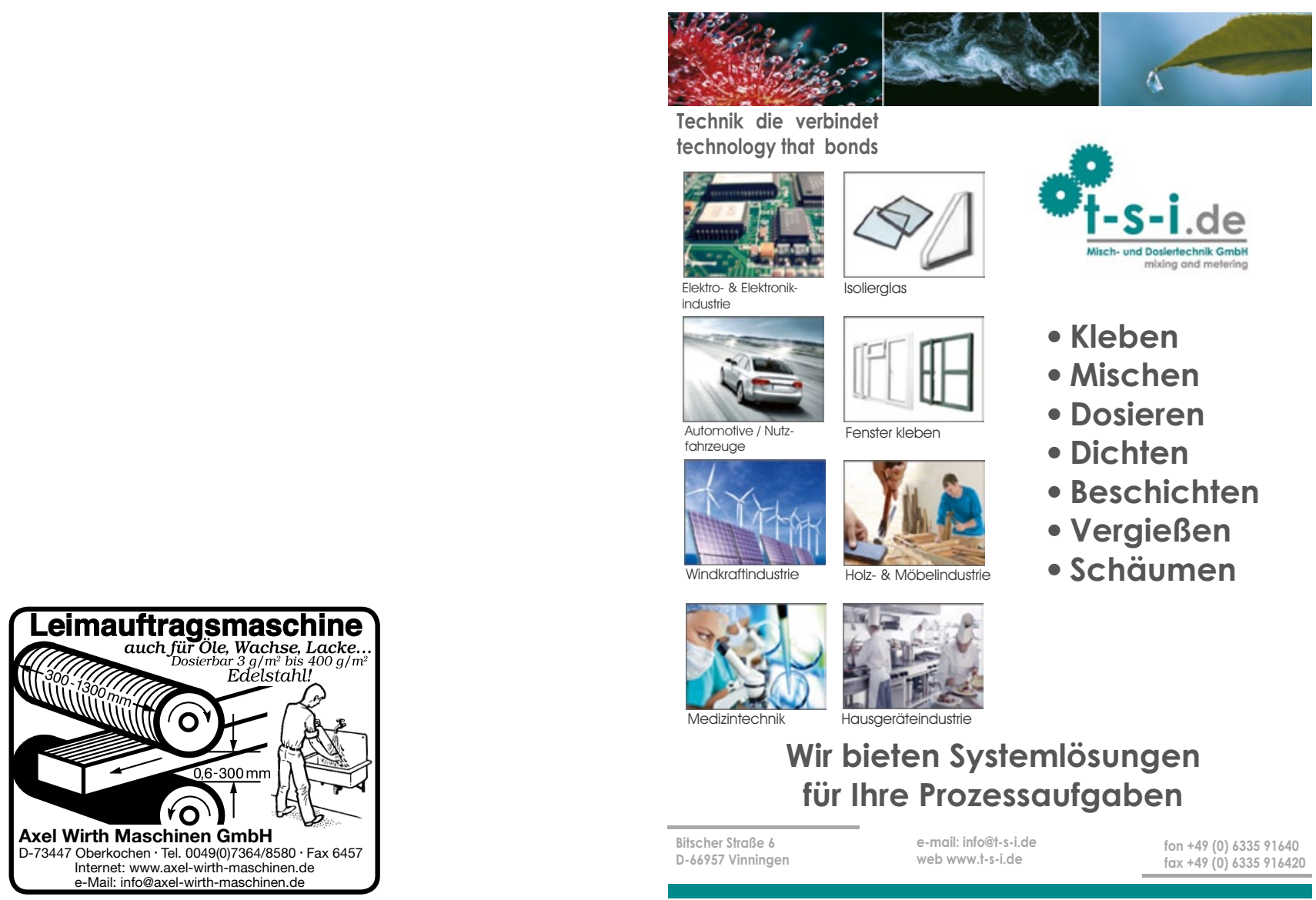